\title{
A STUDY OF 63 CASES OF ATHETOSIS WITH SPECIAL REFERENCE TO HEARING DEFECTS
}

BY

\author{
PATRIA ASHER \\ From the Department of Paediatrics and Child Health, the University of Birmingham
}

(RECEIVED FOR PUBLICATION JANUARY 7, 1952)

In a previous communication (Asher and Schonell, 1950) it was observed that 31 out of 55 cases of athetosis had a history of neonatal jaundice; 19 of these jaundiced babies were proved cases of $\mathrm{Rh}$ iso-immunization. Clinically we could not detect any difference between the various groups of athetoids, classified according to their neonatal history. Meanwhile, Crabtree and Gerrard (1950) had shown that cases of kernikterus are usually deaf or partially deaf. The incidence of hearing defects in athetosis, whatever the apparent aetiology, has now been investigated. The results, together with a study of the neonatal history, appear to cast some light on the aetiology of athetosis. In addition, the diagnosis of deafness has in some cases led to a revision of previous estimates of the child's intelligence, a fact of some practical importance.

\section{Material}

The subjects were patients attending the Spastic Clinic at the Birmingham Children's Hospital. Thirty-nine of those included in the earlier survey were followed up and investigated further, and 24 new cases added. The ages at first attendance ranged from 9 months to 14 years.

\section{Neonatal History}

The high incidence of abnormalities in the neonatal period previously noted has been confirmed. In this series there was a history of prolonged jaundice, birth injury, asphyxia or prematurity in all but seven cases, and in three of these seven labour had been abnormal, suggesting that here, too, some injury might have been sustained.

Cases have been divided into three groups: (1) those with a history of icterus gravis neonatorum due to $\mathrm{Rh}$ iso-immunization (22 cases); (2) those with a history of severe neonatal jaundice without evidence of iso-immunization (12 cases); and (3) those with no history of jaundice ( 29 cases).
(1) Athetosis following Icterus Gravis Neonatorum. In all these 22 cases the child's blood was $R h$ positive and the mother's $\mathrm{Rh}$ negative. In every case the mother had previously borne at least one child. Four cases were premature babies (birth weight $5 \frac{1}{2} \mathrm{lb}$. or less). In three cases labour was abnormal.

These were classical cases of 'kernikterus', using the term to denote the neurological sequelae of icterus gravis. The characteristic neonatal history in such cases is that of a jaundiced baby who seems to do well for a few days in spite of the jaundice. About the fourth day of life a sudden deterioration is noted; the child refuses feeds, becomes cyanosed, or rigid, or collapsed, or twitches or has a fit. The rest of the neonatal period is more or less stormy according to the severity of the case, but the disturbance is often transitory and slight. Such a history was obtained in 13 of these 22 cases.

(2) Athetosis following Neonatal Jaundice without Evidence of Iso-immunization. In these 12 cases the mother's blood was $\mathrm{Rh}$ positive, or both mother and child were $R h$ negative; $R h$ antibodies and anomalous agglutinins were absent in every case. Ten of the 12 babies were firstborn; nine were premature, weighing $3 \mathrm{lb}$. $14 \mathrm{oz}$. to $5 \mathrm{lb} .8 \mathrm{oz}$. at birth (only one weighed less than $4 \mathrm{lb}$.). The full term babies weighed $6 \frac{1}{4} \mathrm{lb}$., $7 \frac{3}{4} \mathrm{lb}$. and $8 \mathrm{lb}$; t two were born after a difficult labour and the third had two convulsions soon after birth. Jaundice was present from the first day in seven cases, and developed within two to six days in the other five. It lasted for two weeks to several months in all but one case, a baby who developed jaundice and had two convulsions on the sixth day; here the jaundice only lasted a few days.

In two cases the child seemed normal at birth; in seven the child was described as 'languid' or 'feeble ', but the babies' progress had not been noted in detail; in three the condition was desperate from the start. In only one case (already noted) 
was there a history of an alarming episode, in this case on the sixth day of life. This was unexpected, for Aidin, Corner and Tovey (1950) reported such a history in most of their 25 cases of fatal kernikterus associated with prematurity, without signs of iso-immunization. However, symptoms would probably be less severe in those who survived, and temporary reluctance to feed in a premature baby might well pass unremarked. Craig (1938) says that cerebral signs may be masked in frail premature infants.

(3) Athetosis in Non-jaundiced Cases. Most of these 29 babies were born after an abnormal labour and showed gross signs of intracranial irritation at birth. Six babies were premature and 18 were firstborn. Labour was abnormal in 19 cases, and 15 of these showed signs of birth-injury or asphyxia. One of the others was a premature baby. Of the 10 babies born after a normal labour, four had signs of cerebral irritation and two of the others were premature.

In only four of these non-jaundiced cases was any sudden deterioration noted a few days after birth. As already mentioned, such signs, if mild, are easily missed, but a striking feature of the usual kernikterus history is that the baby seems to thrive for a few days, in spite of the jaundice, whereas these non-jaundiced babies were mostly gravely ill from the moment of birth, and thereafter made a slow, sometimes incomplete, recovery. Delayed resuscitation, white asphyxia, cyanotic attacks, a cerebral cry, twitching and prolonged difficulty in feeding were all common in their histories. In most cases the baby seemed normal when discharged by hospital or midwife, but one child still had head retraction at 10 days and showed abnormal neurological signs throughout infancy.

\section{Deafness}

Hearing defects are common in kernikterus, being characteristically a perceptive deafness, particularly involving the high tones (Crabtree and Gerrard, 1950). In the present series audiometry was carried out in 42 cases, that is, in nearly all those old enough to cooperate. The results were as follows:-

\begin{tabular}{|c|c|c|c|c|}
\hline & & $\begin{array}{l}\text { Hearing } \\
\text { Defective }\end{array}$ & $\begin{array}{c}\text { Hearing } \\
\text { within } \\
\text { Normal } \\
\text { Limits }\end{array}$ & Not Tested \\
\hline $\begin{array}{l}\text { Jaundiced, } \begin{array}{c}\text { Rh } \\
\text { immunization }\end{array} \\
\text { Jaundiced, no } \\
\text { jmmunization } \\
\text { No jaundice }\end{array}$ & $\begin{array}{c}\text { iso- } \\
\text { iso- } \\
\ldots \\
.\end{array}$ & $\begin{array}{r}12 \\
10 \\
4\end{array}$ & $\begin{array}{r}2 \\
0 \\
14\end{array}$ & $\begin{array}{r}8 \\
2 \\
11\end{array}$ \\
\hline
\end{tabular}

Thus, audiometry showed that hearing defects were present in 22 out of 24 cases tested where neonatal jaundice, of whatever cause, had occurred, and in only four out of 18 non-jaundiced cases. The hearing defect, when present, was generally a high frequency perceptive deafness.

These findings suggest that the distribution of brain lesions is similar in cases of athetosis following neonatal jaundice, whatever the cause of the jaundice, and differs from that in the non-jaundiced cases. The neonatal histories suggest that a different mechanism operates in the non-jaundiced cases.

\section{Discussion}

These findings support the contention of Aidin et al. (1950) that kernikterus is not necessarily associated with iso-immunization. They found nuclear jaundice in 25 infants, 24 of whom were premature, and all of whom had had jaundice. The post-mortem findings were identical with those in fatal cases of kernikterus associated with $R h$ iso-immunization, which was absent in their cases. The fact that the neonatal history, clinical and audiometric findings are so similar in the two groups of jaundiced cases in the present series suggests that the pathological basis is the same in both groups.

The non-jaundiced cases seem to form a separate group; in most of them there was a history of birth injury, and, unlike the jaundiced infants, most of them were gravely ill from the start. Very few of them were deaf. The other neurological findings were, however, identical.

It is difficult to correlate these differences with the corresponding pathology, for, whereas there are many accounts of the post-mortem findings in kernikterus, there is no group of fatal birth injuries in which one can say that, had the child survived, he would have developed athetosis. Bile staining of the floor of the fourth ventricle is common in kernikterus (Becker and Vogel, 1948); damage to the cochlear nucleus is probably the cause of the deafness in these cases, as suggested by Crabtree and Gerrard (1950). They found such damage in one case, and proved that the organ of Corti and auditory nerves were normal. Although this region may be damaged in cases of intracranial haemorrhage (Craig, 1938), this is not common, which might account for the rarity of deafness in athetosis which does not follow neonatal jaundice.

\section{Deafness and Intelligence}

Deaf children seem stupid; often their parents are unaware of their deafness, and attribute their slowness in learning to talk to mental deficiency. Out of 26 children with hearing defects in this series 12 were thought to have normal hearing by 
their parents. In deaf children the standard intelligence tests, for example, the Terman-Merrill, may give misleading results. Seven of our children were therefore re-tested after their deafness had been discovered, using the Drever-Collins test (in which speech is not used) or other tests making allowances for the deafness. In five of these cases the child proved considerably more intelligent than was at first thought. In two cases the original diagnosis of low grade deficiency was confirmed.

\begin{tabular}{|c|c|c|c|}
\hline Case & $\begin{array}{c}\text { I.Q. on } \\
\text { Original Test }\end{array}$ & I.Q. on Re-test & Deafness \\
\hline $\begin{array}{l}\text { J.J. } \\
\text { J.H. } \\
\text { J.H. } \\
\text { J.T. } \\
\text { M.S. }\end{array}$ & $\begin{array}{c}\text { Ineducable } \\
59+ \\
50 \\
60 \\
63+\end{array}$ & $\begin{array}{c}\text { About } 60 \\
80+ \\
\text { About } 75 \\
110 \\
\text { Superior intelligence } \\
\text { (Raven's Matrices) }\end{array}$ & $\begin{array}{l}\text { Severe perceptive } \\
\text { Moderate perceptive } \\
\text { Severe conductive } \\
\text { Severe perceptive } \\
\text { Severe perceptive }\end{array}$ \\
\hline $\begin{array}{l}\text { M.M. } \\
\text { M.J. }\end{array}$ & $\begin{array}{l}\text { Ineducable } \\
\text { Ineducable }\end{array}$ & $\begin{array}{l}\text { Ineducable } \\
\text { Ineducable }\end{array}$ & $\begin{array}{l}\text { Present ? degree } \\
\text { Present ? degree }\end{array}$ \\
\hline
\end{tabular}

Unfortunately it was not possible to re-test all the deaf children, but a study of the notes suggests that at least five-others might prove more intelligent than was at first thought. Thus the I.Q. distribution curve given in our previous paper might have to be shifted to the right for athetoids, but not for spastics, among whom deafness is uncommon. Thus, among 28 spastics only two had hearing defects severe enough to delay speech; none had the typical high frequency perceptive deafness of the athetoid.

It should be emphasized that an athetoid's intelligence is peculiarly hard to assess, quite apart from deafness, as the lack of manual control may make it impossible for him to carry out the actions required in standard intelligence tests, and his speech is often grossly disordered, even when he is not deaf, because of the involuntary movements of lips and tongue. We observed in our previous paper that our assessment of the I.Q. was tentative in many cases and might well prove too low. Further experience has suggested that, whereas the ordinary clinician's guess at the intelligence of a spastic is likely to be reasonably accurate, it is often impossible to guess at the intelligence of an athetoid. The severest athetosis may accompany a high intelligence; one of our patients who could not walk or feed himself till he was in his teens has an I.Q. of 133 . We have never seen a spastic with a comparable physical handicap whose intelligence was anywhere near normal; an intelligent spastic usually has a comparatively slight paralysis.

Thus, no athetoid should be pronounced mentally defective before deafness has been excluded. Quite apart from hearing defects it is difficult to assess an athetoid's intelligence at all accurately; in doubtful cases decision should be postponed for a year or two when the child may have gained a more adequate power of expression.

\section{Summary}

In 63 cases of athetosis there was a history of neonatal jaundice in 34 ; in 22 of these cases $\mathbf{R h}$ iso-immunization was present, and in 12 cases, most of which had been premature babies, it was absent.

In most of the 29 non-jaundiced cases the history suggested that birth injury had occurred.

All but two of the 24 jaundiced cases tested had hearing defects, compared with four out of 18 non-jaundiced cases.

The evidence suggests that athetosis following neonatal jaundice has a similar pathological basis whether or not iso-immunization is the cause.

Deafness may lead to a mistaken diagnosis of mental deficiency in these cases.

My thanks are due to Mr. Crabtree, who directed the otological investigation, to Miss Mundy, who completed the audiograms of so many difficult subjects, to Dr. Wall and his staff for carrying out the intelligence tests and to Dr. J. W. Gerrard, who suggested the research and gave me free access to his unpublished material on kernikterus.

\section{REFERENCES}

Aidin, R. Corner, B. and Tovey, G. (1950). Lancet, 1, 1153 Asher, P. and Schonell, F. E. (1950). Archives of Disease in Childhood, 25, 360.

Becker, P. F. L. and Vogel, P. (1948). J. Neuropath., 7, 190. Crabtree, N. and Gerrard, J. (1950). J. Laryng., 64, 482.

Craig, W. S. (1938). Archives of Disease in Childhood, 13, 89. 